\title{
AS PRÁTICAS SOCIALIZADORAS FAMILIARES COMO LOCUS DE CONSTITUIÇÃO DE DISPOSIÇÕES FACILITADORAS DE LONGEVIDADE ESCOLAR EM MEIOS POPULARES
}

\author{
Maria José Braga Vianna*
}

\begin{abstract}
RESUMO: Este trabalho aborda a problemática das formas de presença das famílias populares na escolarização dos filhos nos casos em que esses últimos logram permanecer no sistema escolar até o ensino superior. Na primeira parte desenvolvo uma revisão de estudos os quais, no campo da sociologia da educação e com base em pesquisas empíricas de porte, enfatizam que esses casos são explicados por uma forte mobilização das famílias. Em seguida, dialogando com outros estudos que sinalizam, em contrapartida, para o fato de que as práticas de mobilização escolar não constituem característica necessária dessas famílias, defendo a pertinência de se verticalizar na investigação das práticas socializadoras familiares, por considerá-las um terreno fértil para a localização de (outras) formas dessa presença, nesse caso pela via da constituição de disposições facilitadoras de longevidade escolar.
\end{abstract}

Palavras-chave: Longevidade escolar. Famílias populares. Relação família-escola. Disposições. Práticas socializadoras familiares.

SOCIALIZATION-FOSTERING FAMILY PRACTICES AS LOCUS OF CONSTITUTION OF DISPOSITIONS TO FACILITATE SCHOOL LONGEVITY IN POPULAR MILIEUS

ABSTRACT: This paper focuses on the problematic ways in which popular families are present in their children's schooling in cases when the latter succeed in remaining in the school system until collegiate education. In the first part I review studies which in the field of Sociology of Education and based on important empirical re-

* Doutora em Educação e professora adjunta da Faculdade de Educação da Universidade Federal de Minas Gerais (UFMG).E-mail: mjbraga@cyberpl.com.br

Educ. Soc., Campinas, vol. 26, n. 90, p. 107-125, Jan./Abr. 2005

Disponível em <http://www.cedes.unicamp.br> 
As práticas socializadoras familiares como locus de constituição...

searches, emphasize that these cases are explained through a strong mobilization of the students' families. Further, considering other studies that demonstrate that scholastic mobilization practices do not constitute the necessary characteristic of these families, I defend the disposition to expand the investigation of socialization-fostering family practices, as I consider they may promote (other) ways in which these families can be present, by means of facilitating dispositions of school longevity.

Key words: School longevity. Popular families. Family-school relationship. Dispositions. Socialization-fostering family practices.

\section{Introdução}

E

ste trabalho representa um esforço de sistematização teórica e elaboração de hipóteses acerca das formas de presença das familias populares na escolarização dos filhos nos casos de longevidade escolar.

Estudos no campo da sociologia da educação têm mostrado que nem sempre os destinos escolares estatisticamente improváveis podem ser explicados pelos processos familiares de mobilização escolar (Laacher, 1990; Lahire, 1997; Viana, 1998). A noção de "mobilização escolar familiar" tem sido entendida no referido campo como atitudes e intervenções práticas voltadas para o rendimento escolar dos filhos, comportamentos e atitudes que mostram ser mais característicos das camadas médias. Esses estudos apontam, a meu ver, para a necessidade de melhor qualificar e caracterizar as relaçóes das famílias de camadas populares com a escola, sinalizando para alguns deslocamentos de foco, um dos quais seria o reconhecimento da existência de um tipo particular de presença familiar na escolarização dos filhos nesses meios. Neste sentido, aproprio-me da seguinte pergunta formulada por Laacher (1990, p. 35): "Em que consiste e como se traduz a presença das famílias populares no sucesso escolar dos filhos?”. Colocando essa indagação como eixo norteador da reflexão, busco desenvolver uma revisão de estudos, uns que demarcam a centralidade da mobilização escolar familiar como condição de sucesso escolar nos meios populares, ${ }^{1}$ outros que apontam para novas possibilidades de abordagem do fenômeno. No diálogo com esses últimos, para além de uma revisão de literatura, dedico-me a construir algumas hipóteses, visando a um aprofundamento na compreensão da problemática. 
Assim, na primeira parte do trabalho apresento, de forma sumária, distintas tendências de análise que, nos anos de 1990, abordam o fenômeno do sucesso escolar em meios populares ${ }^{2}$ de uma perspectiva das exceções estatísticas e dos casos singulares (Laacher, 1990; Lahire, 1997; Laurens, 1992; Portes, 1993; Terrail, 1990; Zéroulou, 1988). Se as pesquisas de Zéroulou e Laurens, por exemplo, apontam que $a$ mobilização escolar familiar foi condição necessária de sucesso escolar dos sujeitos que investigaram, Lahire, por seu turno, defende que essa mobilização não só constitui apenas um dos elementos explicativos, entre outros, e com os quais tece uma relação de interdependência, como, em alguns casos, o investimento escolar dos pais pode surtir até mesmo efeitos contraditórios.

$\mathrm{Na}$ segunda parte, tendo como pressuposto que a mobilização familiar escolar não constitui necessariamente um traço das famílias populares que têm seus filhos no ensino superior, defendo a tese de que existem formas específicas de presença familiar na escolarização dos filhos nos meios populares, a serem identificadas. Verticalizo na hipótese de que algumas dessas formas são produzidas nos processos socializadores familiares, potencialmente produtores de disposiçôes facilitadoras de sobrevida escolar. Aponto, portanto, a necessidade de aprofundar os estudos nesse campo. ${ }^{3}$

Se na primeira parte me apoio fundamentalmente numa literatura francesa, na segunda levanto hipóteses orientadoras para uma pesquisa empírica em andamento, pesquisa que busca mergulhar no estudo de situaçõos inscritas no caso brasileiro e que constitui um desdobramento de questões deixadas em aberto por uma investigação anterior (Viana, 1998).

1. Longevidade escolar no contexto de famílias populares "mobilizadas": alguns resultados de pesquisas empíricas

Resultados de pesquisas empíricas de porte que abordaram o tema do sucesso escolar inesperado de jovens oriundos dos meios populares apontam as práticas educativas familiares de superinvestimento escolar como fatores indispensáveis ao sucesso escolar nessas camadas (Laurens, 1992; Zéroulou, 1988). Para favorecer o sucesso escolar e social de seus filhos, há, nos meios populares, segundo esses auto- 
As práticas socializadoras familiares como locus de constituição...

res, pais que elaboram planos de ação e desenvolvem práticas educativas dotados de uma certa coerência.

Zéroulou aponta essa centralidade já no título de seu trabalho: "O sucesso escolar de filhos de imigrantes - A contribuição de uma abordagem em termos de mobilização" (grifo meu). Essa autora, pioneira nesse campo de estudos, desenvolveu uma pesquisa acerca de casos de êxito escolar de jovens argelinos, cujas famílias eram imigrantes na França. Ela comparou dois grupos de famílias, cujos pais tinham nível socioeconômico semelhante, baixo, mas cujos filhos viveram situações opostas de escolarização: no primeiro, a maioria dos filhos teve acesso à universidade; no segundo, nenhum filho alcançou nem o nível de escolarização que corresponderia, no caso brasileiro, ao ensino médio. Zéroulou conclui que as situações de êxito escolar no interior do primeiro grupo são fruto de mobilizações familiares em torno de um projeto de escolarizar os filhos, defendendo que estas encontram um de seus mais importantes fundamentos numa atitude mais geral de integração cultural, que norteia e define a inserção dessas famílias no universo de chegada/acolhida e, mais especificamente, na escola francesa; o sucesso escolar dos filhos transforma-se, para esses pais, em critério de honra e de legitimação do novo modo de vida construído no movimento de imigração. Essa disposição central favorecedora da escolarização dos filhos se materializa, no cotidiano, por exemplo, no recurso a cursos particulares, na vigilância do estudo extra-classe, numa intensa solidariedade material entre os membros da família, no apelo à memória familiar para, daí, extrair exemplos de sucesso; a escola tornase questão de toda a família. Uma das conclusôes da pesquisa, mais enfatizada pela autora, é a de que essas estratégias se configuram como práticas de superescolarização, conclusão calcada na identificação do alto custo social dessas situações de êxito escolar, por isso surpreendentes, sobretudo se se considera que as probabilidades estatísticas de uma escolarização prolongada para esses sujeitos, no contexto francês, é significativamente pequena.

Laurens estudou trajetórias escolares de filhos de operários franceses que tiveram acesso ao ensino superior de engenharia. A partir de dados estatísticos, conclui que, na França, a chance de um filho de operário ter acesso ao título de engenheiro é da ordem da relação de 1 para 500, o que torna essas trajetórias "singulares, atípicas, extremas, marginais, excepcionais" (Laurens, 1992, p. 2). Essa investigação identificou 
nas famílias uma forte vontade de vencer, sustentáculo de uma determinação capaz de suportar e ultrapassar obstáculos, garantia de apoio em todos os instantes e de instauração de um ambiente concentrado em torno da questão escolar (p. 40).

Esse autor identificou três grupos de famílias, conforme os traços predominantes de seus comportamentos educativos voltados para a escola: os ambiciosos, os laboriosos e os sortudos (respectivamente, 36\%, $42 \%$ e $21 \%$ da população estudada). Os ambiciosos caracterizam-se por uma atitude de assumir riscos na condução da escolaridade dos filhos, cujo horizonte é, desde muito cedo, os ramos mais nobres do ensino superior. Identificam-se, em termos de práticas educativas, por uma busca mais acentuada à pré-escola e à escola privada e pela divisão das tarefas educativas entre os pais. Os laboriosos, por uma implicação e vigilância cotidianas do trabalho educativo: o pai acompanha o trabalho escolar e é bem informado sobre as alternativas de escolarização possíveis e a mãe é fortemente dedicada ao trabalho cotidiano de acompanhamento escolar. No entanto, a despeito desse engajamento, o projeto de escolarização superior para os filhos é formulado tardiamente por um número significativo de famílias desse grupo, o que indica uma atitude de prudência. Os sortudos são identificados por uma estratégia de delegação da orientação escolar a outros "mais competentes", tendo em vista o desconhecimento dos mecanismos de funcionamento do sistema escolar, sobretudo nos níveis secundário e superior. Sob o signo da segurança, essas famílias direcionam as trajetórias escolares dos filhos para os cursos de engenharia de curta duração.

Os dados do estudo de Lahire (1997) não serão tratados aqui, tendo em vista que os seus casos de "sucesso escolar", situando-se no âmbito da escola primária, não podem ser considerados de "longevidade", tal como qualificado neste trabalho. No entanto, defendendo a tese de que "não há um estilo familiar único que leve à conclusão na escola primária”, portanto, a existência de uma diversidade de perfís de sucesso, esse estudo mostra que, em alguns casos, as razões básicas estariam ligadas, sim, às práticas educativas de mobilização escolar. A título de ilustração dessa constatação, destaco dois "perfís" familiares, no interior dos quais o fenômeno da "mobilização familiar" se mostra voltada objetivamente para a questão escolar. O caso de uma menina, intitulado "o investimento escolar" (p. 277-284), tem a mãe como a grande protagonista da escolarização da filha. $\mathrm{O}$ outro caso, também 
As práticas socializadoras familiares como locus de constituição...

de uma menina, qualificado de "ideal" (p. 302-312), centra-se na figura da avó materna, cuja filha, mãe da criança investigada, falecera precocemente.

2. Formas específicas de presença familiar na escolarização dos filhos em contextos populares

\subsection{Ausência ou invisibilidade da família?}

Seria unicamente a mobilização escolar familiar que daria conta dos casos de longevidade escolar nos meios populares? Em não se identificando práticas familiares de mobilização voltadas para a escolarização dos filhos, tal como entendida no contexto dos meios sociais mais favorecidos, que outras formas de presença familiar seriam possíveis? Seriam omissos, ausentes... ou invisíveis os pais, nesses casos?

Uma forte e reiterada constatação das pesquisas acerca das relações das famílias populares com a escola tem sido a de que essas últimas não são omissas e indiferentes com relação à escolarização dos filhos, a despeito da disseminada postura, sobretudo entre professores, de considerá-las demissionárias, apáticas, desmobilizadas. Ou seja, esses estudos negam uma renúncia a priori dessas famílias, um desinteresse pela escola como atitude típica.

Buscando explicações para essas atitudes dos professores, algumas análises as têm situado nas transformaçōes mais recentes do sistema escolar e nas contradições que essas últimas engendram (entre estas a manutenção das desigualdades escolares sob novas formas, justamente quando, paradoxalmente, democratiza-se a escola). A emergência do fenômeno da recomposição do público escolar, que possibilitara o "acesso ao jogo escolar de categorias sociais até então excluídas", sobretudo aos níveis mais elevados de escolarização, teria produzido uma ruptura nos modos tradicionais de relação dos professores com seus alunos (Bourdieu \& Champagne, 1998; De Queiroz, 1995; Charlot, 1997; Dubet, 1997).

Charlot (1997) afirma que, a partir do início dos anos de 1980, em conseqüência das transformaçóes ocorridas no sistema escolar, os professores tiveram que se equilibrar "entre o reconhecimento necessário da heterogeneidade e o cuidado com o universal". Tendo construído 
sua identidade profissional no trato com o "universal" - no campo dos valores, das disciplinas e do saber -, esses professores são confrontados, a partir de então, com a necessidade e o dilema de administrar a heterogeneidade, tendo em vista o acesso generalizado das camadas populares e de minorias étnicas ao sistema de ensino. Instaura-se, assim, para eles, um clima de ruptura e de dificuldades reais advindas daí. Esses professores, tendo que levar em conta e interpretar as formas específicas de inserção das camadas populares no universo escolar, invocam com freqüência a "demissão" dos pais. Esse autor problematiza essa atitude, apoiando-se sobretudo em pesquisas acerca da escolarização de filhos de imigrantes, cujos pais buscam mudar o rumo da própria vida e a de seus filhos por meio do sucesso escolar desses últimos. A esse respeito, afirma categoricamente:

Ora, não há demissão dos pais das famílias populares [com relação à escola], isto é preciso afirmar com veemência! (...) [Nesse domínio] Nós estamos na ordem do sofrimento, da impotência, não da demissão. (...) Ao contrário, os meios populares expressam uma forte demanda com relação à escola. (Charlot, 1997, p. 70)

Lahire (1997) defende, a esse respeito, que a omissão escolar dos pais das camadas populares é um mito produzido pelos professores, especialmente quando aqueles são ausentes do espaço escolar. O termo "omissão", segundo Lahire, é carregado de significado moralizador, que "remete a um voluntário, a uma escolha deliberada", o que não corresponde, segundo ele, ao que apreendeu em sua investigação, acima comentada. Os pais não se mostraram ausentes desse processo, mesmo naqueles casos em que as dissonâncias entre o universo familiar e o escolar são significativas e, dessa forma, constitutivas de situações de fracasso escolar. Três situações de fracasso escolar identificadas em sua pesquisa ilustram esta tese, sendo interpretadas não como omissão dos pais, mas como o resultado da existência de um "elo impossível” entre o universo familiar e o escolar (p. 77-103). São famílias de imigrantes que se caracterizam por uma forte ruptura cultural com relação ao universo escolar, entre as quais prevalece uma atitude de isolamento com relação ao ambiente "exterior" ao familiar supervalorização do "nós" -; os pais opõem uma legitimidade familiar à legitimidade da escola e desenvolvem uma concepção de que a escola seria inteiramente responsável pelo fracasso escolar dos filhos. 
As práticas socializadoras familiares como locus de constituição...

As práticas educativas dessas famílias são marcadas por uma limitada ajuda nos deveres de casa, pela ausência nas reuniōes convocadas pela escola e pela raridade do uso doméstico da leitura e da escrita. Mesmo nesses casos, argumenta o autor, "o fracasso escolar (...) não está necessariamente associado à 'omissão dos pais', mas a uma significativa distância com relação às formas escolares de aprendizagem e de cultura" (p. 87).

Laacher (1990), por sua vez, desenvolve um estudo acerca de trajetórias escolares "de sucesso" de filhos de imigrantes árabes na França, cujos resultados lhe permitem colocar a hipótese da especificidade das formas de intervenção e presença das familias populares na escolarização dos filhos. Essas trajetórias foram identificadas como bem-sucedidas por terem como característica essencial "serem completas, isto é, percursos escolares (...) que culminaram no último estágio de escolaridade" (p. 25). Esse estudo mostra que, em razão tanto da escolarização prolongada alcançada pelos filhos quanto das diferenças das experiências mais gerais de vida, entre elas a da própria experiência da imigração, instaura-se uma descontinuidade cultural e social entre pais e filhos. Essa descontinuidade implica que esses pais, freqüentemente, sobretudo para aqueles cujos filhos alcançaram a universidade,

(...) se constituam como um frágil suporte para as escolhas fundamentais que dizem respeito à escolaridade de seus filhos. (...) nada permite [a esses pais] se colocarem como mediadores e intérpretes da complexidade do funcionamento da instituição escolar. (Laacher, 1990, p. 35)

Essa mesma pesquisa apresentou também duas constatações, aparentemente contraditórias: por um lado, uma ausência quase total dos pais no espaço escolar, por outro lado, reiterados depoimentos dos filhos de que aqueles foram sistematicamente "presentes" em sua trajetória escolar. Laacher defende que não há aí uma contradição, mas coloca, diferentemente, a hipótese da existência de formas específicas de presença familiar na escolarização dos filhos, cuja natureza precisa ser identificada e descrita.

Uma outra possibilidade de abordar a temática/hipótese da "invisibilidade" dos pais de origem popular no processo de escolarização dos filhos é, a meu ver, a dos significados construídos em torno da escola pelas famílias. Os estudos de Charlot $(1996,1997)$ e de 
Charlot \& Rochex (1996) constituem um referencial importante para se pensar a família como um locus privilegiado de produção de significados com relação à escola. A noção de relação com o saber - com o aprender e com a escola - assume centralidade nessa reflexão, uma vez que possibilita a imersão num dos elementos constitutivos do sucesso ou do fracasso escolar, nesse caso pela via das complexas demandas familiares que podem favorecer e sustentar a mobilização (ou a desmobilização) da criança e do jovem com relação à escola. Uma forma de sustentação mobilizadora pode estar, por exemplo, no fato de que, no caso das relações intergeracionais em contextos populares, no plano do simbólico, cada geração autorize a que lhe segue a ser diferente e, portanto, a emancipar-se das origens. Inspirada nessa fonte teórica, em minha tese de doutorado explorei o tema dos processos subjetivos de ruptura, continuidade e ambivalências entre gerações, defendendo a pertinência explicativa dos "sentidos atribuídos à escola e à escolarização pela família e pelo filho-aluno e as diferentes formas de relações intersubjetivas e intergeracionais" daí decorrentes (Viana, 1998, p. 47-59).

Terrail (1997), resenhando as principais contribuições advindas das teses de Charlot e Rochex, acima referidas, aponta quatro tipos possíveis de relação com a escola (e com o saber): 1) de rejeição e renúncia; 2) de interesse nas funções secundárias da escola - principalmente na de socialização no grupo de pares -; 3) de investimento na apropriação de saberes; 4) de interesse na certificação. A novidade da abordagem de Charlot, segundo Terrail, está, por um lado, na diferenciação introduzida entre as atitudes de investimento na apropriação de saberes e de interesse centrado na certificação, normalmente confundidas sob a mesma rubrica de "mobilização" em vista do sucesso escolar, e, por outro, na defesa do caráter menos favorável ao bom desempenho escolar das atitudes mais utilitaristas.

Os processos de significação da escola pelas famílias populares podem ser abordados, ainda, a partir da perspectiva mais ampla da contradição e da ambigüidade - perspectiva que não será objeto de reflexão neste trabalho. Cabe ressaltar apenas que esses traços representam a marca mais contundente das relações das famílias populares com a escola (Nogueira, 1991; De Queiroz, 1981; Thin, 1998; Dubet, 1997). 
As práticas socializadoras familiares como locus de constituição...

2.2. Práticas socializadoras familiares: as diferenças internas às familias populares

Defendo que as práticas socializadoras familiares podem constituir-se como um terreno dos mais importantes para a localização de formas - pouco visíveis - de presença das famílias populares na escolarização dos filhos.

Neste sentido, Thin $(1998)^{4}$ fornece, a meu ver, uma pista interpretativa fértil quando defende que, para trabalhar a relação das camadas populares com a escola, a expressão "práticas socializadoras familiares" torna-se mais pertinente que "práticas educativas familiares", tendo em vista que o sentido historicamente dominante de "práticas educativas familiares" não corresponde ao que efetivamente se passa na realidade dessa relação específica. $\mathrm{O}$ autor argumenta que "nessas famílias, a criança não é constituída como objeto de educação ou como ser a educar, ou seja, não é considerada objeto de uma ação específica, sistemática e sensivelmente diferente, relativamente separada de outras atividades familiares" (p. 93-94). Não que não se cuide dos filhos nessas famílias, mas o sentido central de sua tese é a de que "não há uma intenção pedagógica” em suas práticas. Assim, a idéia que o termo socialização carrega seria mais apropriada, porque a ação educativa dessas famílias se mostra marcadamente difusa, como "uma atenção mais lateral que direta”.

A pesquisa de Thin identificou alguns traços fortes do modo de socialização nas famílias populares, modo que se produz por meio de práticas "não-escolares" (p. 94-126). Um desses traços diz respeito ao "sentido prático": um tipo de formação "não-pedagógico", ou seja, não normatizado por saberes teóricos, sem contornos marcadamente reflexivos, mas, diferentemente, processado diretamente nas atividades práticas, cotidianas, por imitação e imersão. O autor extrai estas conclusões de algumas práticas familiares que considera "particularmente exemplares e significativas", como os passeios e jogos partilhados com os filhos. Presididas por uma lógica diferente daquela que está muito presente em meios sociais mais favorecidos, essas atividades, não permeadas pela dimensão do "cultural", não são consideradas pelos pais ocasiões de desenvolvimento cognitivo dos filhos. Nas entrevistas, os pais não desenvolvem nenhum discurso sobre as virtudes formadoras dessas atividades. 
Um modo de autoridade que se define pelas "sanções imediatas e contextualizadas" constitui um outro traço do modo de socialização nessas famílias. As sanções prevalecem sobre sua justificação; as punições são pouco discutíveis ou negociáveis: "A moral que é associada [à punição] ou que a subentende, não é explicitada, ou pouco explicitada" (p. 115). Ou seja, essas práticas não favorecem a interiorização de princípios de comportamento, de autonomia, porque "a autoridade é inseparável do contexto no qual ela se aplica” (p. 117).

Por sua vez, a escola, uma invenção moderna, realiza um modo de socialização próprio, nomeado por Vincent (1994) forma ou modo escolar de socialização. Dentre os traços centrais dessa forma de socialização destacam-se: por um lado, sua oposição ao modo de socialização prático, presente de forma contundente nas famílias de camadas populares e, por outro lado, sua autonomia com relação às práticas socializadoras exercidas no contexto social mais amplo; o que confere a esse modo de socialização uma demarcação como "relação pedagógica" (De Queiroz, 1995; Thin, 1998; Vincent, 1994). Rompendo com modos de socialização anteriores, a escola passa a se constituir como um espaço sociocultural original, dotado de um poder próprio, colocando-se, nos dias atuais, numa situação de "interioridade externa" ao campo social (De Queiroz, 1995).

No que diz respeito às relações entre as famílias populares e a escola, Thin demarca que essas relaçôes se desenrolam no contexto de um confronto desigual, tenso, constitutivo de dificuldades reais para professores e famílias, dificuldades que são estruturais - não apenas mal-entendidos - porque produto de uma oposição profunda entre duas lógicas sociais diferentes, muitas vezes contraditórias. Há uma forte contradição entre as lógicas que orientam as práticas das famílias populares e as lógicas escolares. Em dois domínios, particularmente, as lógicas das famílias populares chocam-se com as escolares, segundo esse autor: o do "modo de autoridade" e o da "relação com a escolaridade". Quanto ao modo de autoridade, ao passo que a escola valoriza e exige autonomia, a autoridade dos pais populares ancora-se sobre o princípio da vigilância exterior direta, conforme discutido acima. Quanto ao sentido atribuído à escolaridade dos filhos, o desencontro família-escola dá-se na medida em que, ao passo que as famílias se orientam sobretudo pela "lógica da eficácia" - aprendizagens escolares que devem culminar em trunfos profissionais e possi- 
As práticas socializadoras familiares como locus de constituição...

bilitar um "se virar" na vida, por exemplo -, muitas ações pedagógicas escolares distanciam-se desse objetivo.

Essa confrontação desigual tem também como princípio a existência de uma rede complexa de interdependências entre esses dois modos de socialização. A noção de configuração social tem aqui um importante potencial explicativo, a meu ver (Elias, 1990, 1991; Lahire, 1997). Por um lado, as lógicas escolares tendem a se impor às famílias populares; por outro, essas últimas dominam precariamente as regras da vida escolar e vivenciam como ilegítimas as suas formas de educar os filhos, apesar de atribuírem importância à escolarização dos filhos. Assim, envolvidas em contradiçôes, vêem-se submetidas à necessidade de escolarizá-los.

No entanto, mesmo predominando um confronto desigual entre famílias populares e escola no que diz respeito aos modos de socialização predominantes e específicos em cada um desses universos, contraditórios muitas vezes, busco uma brecha de análise nas diferenças internas a essas mesmas famílias. Essa heterogeneidade interna possibilitaria a emergência de situações de menor distanciamento com relação à escola. O próprio Thin (1998) argumenta que a existência de um modo popular de socialização, como traço comum, dominante, não exclui a possibilidade - e a existência de fato - de variaçôes no interior das lógicas que tramam essa socialização, nem a heterogeneidade das práticas e, portanto, de universos familiares em menor contradição com as exigências escolares.

O destaque de traços constitutivos das lógicas socializadoras populares, que tem como objetivo apontar as contradições fundamentais com as lógicas escolares, não nos leva a esquecer a fecundidade heurística das pesquisas que tomam como objeto de estudo as diferenças das práticas socializadoras no interior das famílias populares. (Thin, 1998, p. 95)

"Diferenças secundárias" estariam presentes em situações familiares que, de maneira atípica, produzem disposições de autonomia, inculcam determinadas regras e determinados tipos de moral. A presença das famílias populares na escolarização dos filhos em situação de longevidade escolar, objeto de reflexão do presente trabalho, estaria sendo pensada, assim, pela via da constituição de disposições facilitadoras e na perspectiva da complexa interdependência entre a escola e a família. A esse respeito, busco novamente apoio em Lahire (1997, p. 19): 
Se a família e a escola podem ser consideradas redes de interdependências estruturadas por formas de relações sociais específicas, então o "fracasso" ou o "sucesso" escolares podem ser apreendidos como o resultado de uma maior ou menor contradição, do grau mais ou menos elevado de dissonância ou de concordância das formas de relaçóes sociais de uma rede de interdependência a outra.

Neste sentido, os estudos de Laacher (1990) e Lahire (1997) constituem referências importantes para a discussão desta questão, sobretudo porque amparados em base empírica. Embora partindo de metodologias próprias e temáticas distintas, as "práticas socializadoras familiares" são por eles apontadas como um dos fatores explicativos do sucesso ou do fracasso escolar em famílias populares. Laacher coloca a hipótese de que essas famílias "são dotadas de uma moral educativa, de uma educação governada pela prudência, mas também e, talvez, sobretudo, pela perseverança". No contexto da pesquisa desse autor, essa moral educativa encontra seus lastros principalmente na experiência de imigração, atormentada por uma obsessão ética de produzir filhos "honestos", muito mais que alunos brilhantes. No entanto, embora essa moral educativa não esteja centrada na escolarização, constitui uma dimensão importante dela:

(...) é muito mais a compreensão das condições de produção dessa moral, de seu modo de funcionamento e de sua interiorização pelos membros do grupo, do lugar e do tratamento que ela reserva à escola que se pode compreender a relação dessas famílias com a instituição escolar. (Laacher, 1990, p. 35)

Lahire não só defende que as "diferenças secundárias" no interior das famílias populares constituem pressuposto básico de sua explicação para o sucesso e o fracasso escolares (na escola primária) como atribui um peso significativo às práticas socializadoras familiares, colocando-as entre os "traços pertinentes para a leitura sociológica" dos dados de sua pesquisa. Sua inserção nesse campo se deu pela via das condições e disposiçóes econômicas, da ordem moral doméstica e das formas de autoridade familiar. A importância de uma "ordem moral doméstica", por exemplo, estaria no fato de que ela se vincula estreitamente a uma ordem cognitiva, favorecedora, entre outras coisas, de um bom desempenho escolar: "a regularidade das atividades, dos horários, das regras de vida rigorosas e recorrentes, as ordenaçôes, os arranjos ou as classificações domésticas, produzem estruturas cognitivas ordenadas, capazes de colocar em ordem, de dirigir, de ordenar pensamentos" (Lahire, 1997). 
As práticas socializadoras familiares como locus de constituição...

Os quatro casos de "brilhantes sucessos" (p. 285-333) que identifica são esclarecedores a respeito do que aqui se discute. $\mathrm{Na}$ análise de um desses casos - intitulado "Aqui tudo é ordem e regularidade" (p. 288-296) -, o autor descreve as conseqüências de uma socialização difusa, produtora de "um ethos familiar muito coerente, regular e sistematicamente posto em prática e, por isso, potente em seus resultados" (p. 296).

Incluo ainda Terrail (1990) entre os autores nos quais me apoio para pensar o peso da socialização familiar na produção do fenômeno da longevidade escolar em meios populares. Esse autor focaliza sua atenção na socialização mais geral que ocorre no universo dessas famílias, mais especificamente nas lógicas que presidem suas relações com a sociedade mais ampla, e, nesse contexto, com o pertencimento de classe. Dos três tipos de famílias que ele identificou em seu estudo acerca de trajetórias escolares de intelectuais de origem operária, um mostrouse particularmente impulsionador na elaboração de projetos de escolarização prolongada para os filhos. São famílias que, embora mantendo vínculos com a identidade operária, caracterizam-se pelo desejo de "apropriação do mundo", de ampliação de horizontes para além do universo estrito de classe e do fechamento em seu mundo de cultura (Terrail, 1990, p. 228).

Finalmente, busco apoio nos resultados de minha própria investigação, realizada anteriormente, para defender a idéia de que determinadas disposiçôes temporais se mostram favorecedoras de longevidade escolar (Viana, 1998). ${ }^{5}$ Extraio desse estudo a conclusão que se segue, mantendo-a como hipótese para aprofundamento.

(...) um dos traços explicativos de longevidade escolar nas camadas populares está ligado com a extensão do horizonte temporal de futuro, com a possibilidade - sobretudo na sua dimensão subjetiva - que isso implica de construir planos de vida, com uma disposição dominante de conquista em relação ao futuro e com uma orientação básica temporal de perseverança. (Viana, 1998, p. 65)

\section{Considerações finais}

Para concluir, retomo reflexões desenvolvidas neste trabalho.

No que diz respeito à revisão de literatura, apresentei estudos que, 
apoiados em dados empíricos, sustentam a tese de que as escolaridades prolongadas em meios populares supõem uma forte mobilização familiar. A esse respeito, alguns estudos mostram, ainda, que o engajamento dos pais, embora indispensável, não é suficiente para que os filhos logrem êxito na escola; é necessária a aplicação desses últimos no próprio processo de escolarização, de maneira autônoma, sobretudo nos meios populares. Enfatiza-se, assim, que o sucesso escolar não é redutível à mobilização dos pais - dependendo dela apenas parcialmente - e que a mobilização familiar teria duas faces, a dos pais e a dos filhos/jovens (Terrail, 2002; De Singly, 1996).

Este trabalho tentou argumentar, também, em torno de outras hipóteses explicativas para o fenômeno da longevidade escolar em famílias populares e, neste sentido, arriscou-se de uma maneira propositiva. Defendi que os processos de socialização familiar, produtores de traços disposicionais, são potencialmente desencadeadores de elementos favorecedores - ou dificultadores - de êxito escolar, conforme as afinidades ou os distanciamentos com relação à escola que esses traços engendram.

A principal hipótese que elaboro é a de que, no interior dos processos de socialização familiar nos meios populares - sobretudo nas brechas, a serem exploradas, de suas diferenças internas -, podem ser vislumbradas pistas para identificação de formas específicas de presença das famílias na escolarização dos filhos, presença que não significa, necessariamente, mobilização escolar stricto sensu.

\section{Recebido em setembro de 2004 e aprovado em março de 2005.}

\section{Notas}

1. Zago (2000), com outros objetivos, produziu revisão semelhante.

2. No contexto dos estudos que venho realizando, qualifico como sucesso escolar o acesso ao ensino superior, o qual, mais apropriadamente, a meu ver, denomino de longevidade escolar.

3. Esse interesse de aprofundamento está na origem do problema norteador de uma investigação que atualmente desenvolvo, cujo projeto se intitula Formas especificas de presença das familias das camadas populares na escolarização dos filhos - Casos de longevidade escolar. Esse projeto se vincula, por sua vez, ao projeto integrado de pesquisa: $A$ construção da longevidade $e$ da excelência escolar em famílias de diferentes meios sociais: processos e práticas de escolarização (FAE-UFMG).

Educ. Soc., Campinas, vol. 26, n. 90, p. 107-125, Jan./Abr. 2005 
As práticas socializadoras familiares como locus de constituição...

4. Thin desenvolveu uma pesquisa em cinco escolas localizadas em dois bairros de periferia da cidade de Lyon, na França, bairros habitados por famílias populares, muitas de origem estrangeira e inseridas num contexto de grandes dificuldades econômicas. Seu interesse de estudo centrou-se na busca do "sentido sociológico" das relações entre professores, "assistentes sociais" e famílias populares. Mais especificamente, esse autor se propôs a elucidar "a maneira pela qual seres sociais e lógicas diferentes se confrontam nessas relações" (1998, p. 6).

5. Naquele trabalho, inspiro-me sobretudo no conceito de "temporalidades sociais" de Mercure (1995) para explorar a questão das disposições temporais. Exploro também, de forma mais detalhada, as disposições e condutas com relação ao tempo que são favorecedoras de longevidade escolar em famílias populares, em trabalho recente intitulado Os processos de escolarização prolongada em meios populares: a presença da família pela via da constituição de disposições facilitadoras, apresentado na Conferência Internacional de Sociologia, ISA, Buenos Aires, 25-28 ago. 2004.

\section{Referências bibliográficas}

ABREU, R.C. Famílias de camadas populares e Programa Escola Plural: as lógicas de uma relação. 2002. Dissertação (mestrado) - Faculdade de Educação. Universidade Federal de Minas Gerais, Belo Horizonte.

BOURDIEU, P. A escola conservadora: as desigualdades frente à escola e à cultura. In: Nogueira, M.A.; CATANI, A. (Org.). Escritos de educação. Petrópolis: Vozes, 1998. p. 39-64.

BOURDIEU, P.; CHAMPAGNE, P. Os excluídos do interior. In: Bourdieu, P. (Org.). A miséria do mundo. Petrópolis: Vozes, 1998. p. 481-486.

CHARLOT, B. Relação com o saber e com a escola entre estudantes de periferia. Cadernos de Pesquisa, São Paulo, n. 97, p. 47-63, 1996 (Tradução Neide Luzia de Rezende).

CHARLOT, B. Pour le savoir, contre la stratégie. In: Dubet, F. (Org.). École, famille: le malentendu. Paris: Éditions Textuel, 1997. p. 59-78.

CHARLOT, B.; ROCHEX, J.-Y. L’enfant-élève: dinamiques familiales et expérience scolaire. In: De SinglY, F.; Bernier, L. (Org.). Lien social et politiques - Familles et école. Quebec: RIAC, n. 35, 1996. p. 75-85.

DE QUEIROZ, J.-M. L école et ses sociologies. Paris: Éditions Nathan, 1995. 
DE QUEIROZ, J.-M. Les familles et lథécole. In: De Singly, F. La famille: l'état de savoirs. Paris: La Découvert, 1991. p. 201-210.

DE SINGLY, F. La mobilisation familiale pour le capital scolaire. In: Dubet, F. (Org.). École, famille: le malentendu. Paris: Éditions Textuel, 1997. p. 45-58.

DE SINGLY, F. L'appropriation de l'héritage culturel. In: De SingLY, F.; Bernier, L. (Org.). Lien social et politiques - Familles et école. Quebec: RIAC, n. 35, 1996. p. 153-165.

DUBET, F. École, familles: le malentendu (Sommaire). Paris: Éditions Textuel, 1997. p. 11-42

DURU-BELLAT, M. Les inégalités sociales de reussite: inégalités de compétences, d'héritages, de moblisation? In: Duru-Bellat, M. Les inégalités sociales à l'école - Genèse et mythes. Paris: PUF, 2002. p. 178-187.

ELIAS, N. A sociedade dos individuos. Rio de Janeiro, Zahar, 1990.

ELIAS, N. Qu'est-ce que la sociologie? Paris: Éditions de l'Aube, 1991.

LAACHER, S. L'école et ses miracles: notes sur les déterminants sociaux des trajectoires scolaires des enfants de familles immigrées. Politix, Paris, n. 12, p. 25-37, 1990.

LAHIRE, B. La théorie de l'habitus à une sociologie psychologique. In: LAHIRE, B. (Org.). Le travail sociologique de Pierre Bourdieu - Dettes e critiques. Paris: La Découverte, 2001. p. 121-152.

LAHIRE, B. Sucesso escolar nos meios populares: as razões do improvável. Tradução de Ramon Américo Vasques e Sonia Goldefer. São Paulo: Ática, 1997.

LAURENS, J.-P. 1 sur 500 - La réussite scolaire en milieu populaire. Tolouse: Presses Universistaires du Mirail, 1992.

MERCURE, D. Les temporalités sociales. Paris: Éditions L'Harmattan, 1995.

NOGUEIRA, M.A. Trajetórias escolares, estratégias culturais e classes sociais; notas em vista da construção do objeto de pesquisa. Teoria \& educação, Porto Alegre, n. 3, p. 89-112, 1991. 
As práticas socializadoras familiares como locus de constituição...

NOGUEIRA, M A. Relação família-escola: novo objeto na sociologia da educação. Paidéia, Ribeirão Preto, fFClRP-Usp, p. 91-101, 1998.

NOGUEIRA, M.A; ABREU, R.C. Famílias populares e escola pública: uma relação dissonante. Belo Horizonte (artigo submetido à Educação em Revista, 2003).

PORTES, E.A. Trajetórias e estratégias escolares do universitário das camadas populares. 1993. Dissertação (mestrado) - Faculdade de Educação. Universidade Federal de Minas Gerais, Belo Horizonte.

SOUZA E SILVA, J. Por que uns e não outros? Caminhada de estudantes da Maré para a Universidade. 1999. Tese (doutorado) Pontifícia Universidade Católica do Rio de Janeiro, Rio de Janeiro.

TERRAIL, J.-P. L'issue scolaire: de quelques histoires de transfuges. In: Terrail, J.-P. Destins ouvriers - La fin d'une classe? Paris: PUF, 1990. p. 223-258.

TERRAIL, J.-P. La Sociologie des interactions famille-école. Sociétés contemporaines, n. 25, p. 67-83, 1997.

TERRAIL, J.-P. Du sens de l'auto-exclusion/La mobilisation contre les probalilités. In: Terrail, J.-P. De l'inégalité scolaire. Paris: La Dispute/SNÉDIT, 2002. p. 46-54.

THIN, D. Quartiers populaires - L'école et les familles. Lyon: PUL, 1998.

VAN-ZANTEN, A.H. Les pratiques éducatives des familles. In: VANZanten, A.H. Sociologie de l'école. Paris: Armand Colin, 1999. p. 169-188.

VIANA, M.J.B. Novas abordagens da escolarização das camadas populares: uma revisão de estudos recentes acerca de trajetórias escolares de sucesso. Vertentes, São João del-Rei, UfSJ, n. 7, p. 82-93, 1996.

VIANA, M.J.B. Longevidade escolar em famílias de camadas populares: algumas condiçóes de possibilidade. 1998. Tese (doutorado) - Faculdade de Educação. Universidade Federal de Minas Gerais, Belo Horizonte.

VIANA, M.J.B. Longevidade escolar em famílias de camadas populares: algumas condiçôes de possibilidade. In: Nogueira, M.A; RomA- 
Nelli, G.; ZAGo, N. Família \& Escola - Trajetórias de escolarização em camadas médias e populares. Petrópolis: Vozes, 2000. p. 45-60.

VINCENT, G. L'Éducation prisonnière de la forme scolaire? Scolarisation et socialisation dans les sociétés industrielles. Lyon: PUL, 1994.

VINCENT, G; LAHIRE, B.; THIN, D. Sobre a história e a teoria da forma escolar. Educação em Revista, Belo Horizonte, n. 33, p. 7-47, 2001.

ZAGO, N. Quando os dados contrariam as previsões estatísticas: os casos de êxito escolar nas camadas socialmente desfavorecidas. Paidéia, Ribeirão Preto, FFCLRP-USP, p. 70-80, 2000.

ZÉROULOU, Z. La réussite scolaire des enfants d'immigrés: l'apport d'une approche en termes de mobilisation. Revue Française de Sociologie, v. 29, n. 3, p. 447-40, 1988. 